\title{
Efeito da temperatura de queima em composição de massa para revestimento cerâmico vitrificado com argila caulinítica e nefelina sienito
}

\section{(Effect of the firing temperature on the body composition for vitrified ceramic tiles with kaolinitic clay and nepheline-syenite)}

\author{
K. O. Teixeira, S. N. Monteiro, C. M. F. Vieira \\ Laboratório de Materiais Avançados - LAMAV, Universidade Estadual do Norte Fluminense Darcy Ribeiro - \\ UENF, Av. Alberto Lamego 2000, Campos dos Goytacazes, RJ 28013-602 \\ kenia.uenf@gmail.com,sergio.neves@ig.com.br,vieira@uenf.br
}

\begin{abstract}
Resumo
Este trabalho tem por objetivo desenvolver formulação de massa para revestimento cerâmico vitrificado utilizando o fundente nefelina sienito com argila caulinítica. Foram preparadas formulações com 0,30 e 50\% em peso de nefelina sienito em mistura com a argila. Corpos-de-prova foram obtidos por prensagem uniaxial a $30 \mathrm{MPa}$ para queima nas temperaturas de $1100{ }^{\circ} \mathrm{C}, 1150{ }^{\circ} \mathrm{C}$ e $1200{ }^{\circ} \mathrm{C}$. As propriedades físicas e mecânicas avaliadas foram: densidade aparente a seco, retração linear, tensão de ruptura à flexão e absorção de água. A microestrutura das cerâmicas queimadas foi avaliada por microscopia eletrônica de varredura e difração de raios X. Os resultados indicaram que a incorporação de nefelina sienito melhorou significativamente as propriedades da argila possibilitando alcançar a especificação de revestimento cerâmico vitrificado.

Palavras-chave: argila caulinítica, fundente, nefelina sienito, revestimento cerâmico.
\end{abstract}

Abstract

This work had for objective to development vitrified ceramic tiles body using the nepheline-syenite flux with a kaolinitic clay. Formulations were prepared with addition of 0, 30 and $50 \mathrm{wt} . \%$ of nepheline-syenite to the clay. Specimens were prepared by uniaxial pressure at $30 \mathrm{MPa}$ followed by firing at 1100,1150 and $1200^{\circ} \mathrm{C}$. The evaluated physical and mechanical properties were: dry bulk density, linear shrinkage, three point bending mechanical strength and water absorption. The microstructure of the fired ceramics was evaluated by scanning electron microscopy and $X$-ray diffraction. The results showed that the incorporation of nepheline-syenite significantly enhanced the properties of the clay making it possible to reach the specification of vitrified ceramic tiles.

Keywords: kaolinitic clay, flux, nepheline-syenite, ceramic tiles.

\section{INTRODUÇ̃̃̃O}

Massas cerâmicas utilizadas para a fabricação de revestimento vitrificado são geralmente elaboradas a partir de uma mistura de diversas matérias-primas que podem ser agrupadas, por exemplo, em plásticas, inertes, fundentes e modificadores de fundência [1]. Em casos específicos, determinadas tipologias de revestimento cerâmico são obtidas por meio da mistura de um único tipo de matéria-prima, a argila. Como a argila apresenta, além do argilomineral, outros constituintes como impureza, tais como quartzo, feldspatos, carbonatos, etc, a constituição química e mineralógica de determinadas argilas pode ser adequada para a obtenção de revestimento cerâmico, mesmo aplicando-se uma tecnologia de ponta atualmente disponível. Isto significa que é possível obter revestimento cerâmico utilizando-se desde uma única argila a uma mistura complexa de diversas matérias-primas. Partindo-se da premissa que a argila, devido ao aporte de plasticidade em mistura com água, é essencial numa formulação de massa, as demais matérias-primas podem ser misturadas à argila para corrigir eventuais deficiências em função do processamento e dos requisitos técnicos desejados.

Desta forma, este trabalho tem por objetivo formular uma massa cerâmica para revestimento vitrificado, pertencente ao grupo BIb [2], que deve apresentar absorção de água média entre 0,5 e $3 \%$ e tensão de ruptura à flexão $\geq 30 \mathrm{MPa}$, conforme indicado na Tabela I, utilizando uma mistura de argila caulinítica com o fundente nefelina sienito.

Nefelina sienito é uma rocha ígnea alcalina constituída predominantemente por feldspatos [3]. Diversos trabalhos investigaram o uso da nefelina sienito com fundente para a indústria cerâmica, sobretudo, em substituição ao tradicional feldspato [4-10], com resultados geralmente bastante satisfatórios. A mistura nefelina sienito/argila caulinítica foi estudada para a produção de revestimento cerâmico gresificado [10]. Foram preparadas formulações com $0 \%, 30 \%$ e $50 \%$ em peso de nefelina sienito em mistura com a argila, com e sem a adição de 3,5\% em peso de talco para queima a $1175{ }^{\circ} \mathrm{C}$. Os resultados indicaram que a 
Tabela I - Classificação de revestimento cerâmico prensado em função da absorção de água e da tensão de ruptura à flexão [2].

[Table I - Classification of pressed ceramic tiles as a function the water absorption and flexural rupture strength [2].]

\begin{tabular}{|c|c|c|c|c|c|}
\hline \multirow{2}{*}{ PROPRIEDADES } & \multicolumn{5}{|c|}{ GRUPOS } \\
\hline & BIa & BIb & BIIa & BIIb & BIII \\
\hline Absorção de Água - AA (\%) & $\mathrm{AA} \leq 0,5$ & $0,5<\mathrm{AA} \leq 3$ & $3<\mathrm{AA} \leq 6$ & $6<\mathrm{AA} \leq 10$ & $\mathrm{AA}>10$ \\
\hline $\begin{array}{l}\text { Tensão de Ruptura à } \\
\text { Flexão TRF (MPa) }\end{array}$ & $\mathrm{TRF} \geq 35$ & $\mathrm{TRF} \geq 30$ & $\mathrm{TRF} \geq 22$ & $\mathrm{TRF} \geq 18$ & $\begin{array}{l}\geq 12^{*} \\
\geq 15^{* *}\end{array}$ \\
\hline
\end{tabular}

"espessura $<7,5 \mathrm{~mm}$. " espessura $\geq 7,5 \mathrm{~mm}$.

utilização de $30 \%$ em peso de nefelina sienito possibilitou uma melhoria significativa nas propriedades de queima da argila caulinítica permitindo alcançar as especificações de revestimento cerâmico do tipo semi-grês (grupo BIIa), absorção de água na faixa de $3-6 \%$ e tensão de ruptura à flexão igual ou superior a $22 \mathrm{MPa}$. Já a utilização de $50 \%$ possibilitou alcançar as especificações de revestimento cerâmico do tipo grês (grupo BIb), absorção de água na faixa de $0,5-3 \%$ e tensão de ruptura à flexão igual ou superior a $30 \mathrm{MPa}$. A utilização adicional de talco melhorou ainda mais as propriedades de queima da cerâmica. Entretanto, não possibilitou alcançar as especificações, com respeito à absorção de água e tensão de ruptura à flexão, de porcelanato, grupo BIa.

O presente trabalho teve como objetivo dar continuidade à pesquisa [10], investigando o efeito da variação da temperatura de queima nas propriedades físicas e mecânicas de cerâmica para revestimento vitrificado elaborada com nefelina sienito e argila caulinítica.

\section{MATERIAIS E MÉTODOS}

Foram utilizados os seguintes materiais: argila caulinítica e nefelina sienito. A argila, de coloração cinza e de elevada plasticidade, é empregada em composição de massa de cerâmica vermelha pelas indústrias do pólo cerâmico de Campos dos Goytacazes, RJ. A argila é constituída predominantemente de caulinita, quartzo, mica e hidróxidos de alumínio e de ferro [11]. Já a nefelina sienito, com tamanho de partícula inferior a 325 mesh $(0,044 \mathrm{~mm})$, foi adquirida de uma pedreira localizada no município de Nova Iguaçu, RJ. A composição mineralógica semi-quantitativa da nefelina sienito é de aproximadamente $90 \%$ em peso de feldspatos alcalinos. Os demais constituintes são: dolomita, pirita, nefelina/sodalita, monazita, biotita e limonita [3]. Foram preparadas formulações com incorporação de nefelina sienito na argila nas seguintes quantidades: 0 (A), $30(\mathrm{~A} 30 \mathrm{~N})$ e $50(\mathrm{~A} 50 \mathrm{~N}) \%$ em peso. Corpos-de-prova retangulares $(11,43 \times 2,54 \times 0,8 \mathrm{~cm})$ foram elaborados por prensagem uniaxial a $30 \mathrm{MPa}$ com $8 \%$ de umidade. Em seguida, os corpos-de-prova foram secos em estufa a $110^{\circ} \mathrm{C}$ por $24 \mathrm{~h}$. A etapa de queima foi realizada em forno de laboratório nas temperaturas de 1100,1150 e $1200{ }^{\circ} \mathrm{C}$. As temperaturas utilizadas foram baseadas nas curvas dilatométricas das formulações apresentadas no trabalho anterior [10], bem como nas temperaturas industriais. A taxa de aquecimento empregada foi de $10^{\circ} \mathrm{C} / \mathrm{min}$, com 6 min na temperatura de patamar. $\mathrm{O}$ resfriamento foi realizado desligando-se o forno. Após queima, cinco corpos-deprova de cada formulação foram submetidos aos seguintes ensaios: densidade aparente a seco e de queima, retração linear, absorção de água e tensão de ruptura por flexão em 3 pontos, de acordo com procedimentos padronizados [12, 13]. A análise microestrutural foi realizada por meio da observação da superfície de fratura das cerâmicas utilizando um microscópio eletrônico de varredura Shimadzu SSX-550 e por difração de raios X com um difratômetro Shimadzu DXR 7000, com radiação Cu-ka.

\section{RESULTADOS E DISCUSSÃO}

A densidade aparente a seco das cerâmicas é apresentada na Fig. 1. É possível observar que a utilização de nefelina sienito possibilitou uma melhora significativa na densificação da argila. Isto é atribuído à granulometria mais grosseira da nefelina sienito em comparação com a argila, possibilitando um melhor empacotamento das partículas durante a etapa de conformação. O aumento na densidade a seco é benéfico no sentido de facilitar as reações de sinterização durante a etapa de queima e reduzir a retração. Por outro lado, um maior empacotamento das partículas pode dificultar a saída de gases durante o estágio inicial de queima acarretando problemas nas peças.

As Figs. 2 a 4 apresentam as propriedades físicas e mecânicas das cerâmicas queimadas. De uma maneira geral, a utilização de nefelina sienito possibilitou uma melhora significativa nas propriedades da argila. Isto ocorreu devido à ação fundente da nefelina sienito que promoveu uma redução significativa da porosidade de queima da argila. A Fig. 2 apresenta a absorção de água das cerâmicas em função da temperatura de queima. Pode-se observar que a incorporação de nefelina sienito melhorou a absorção de água da argila em todas as temperaturas investigadas. A $1100{ }^{\circ} \mathrm{C}$ não foi possível alcançar a especificação de revestimento tipo semi-grês, absorção de água entre 3 a $6 \%$, e grês, absorção de água entre 0,5 e $3 \%$, para nenhuma cerâmica. Já a $1150{ }^{\circ} \mathrm{C}$ a incorporação de $30 \%$ de nefelina possibilitou alcançar absorção de água compatível com revestimento tipo semi-grês. Já a incorporação de $50 \%$ de nefelina sienito possibilitou alcançar valor de absorção de 


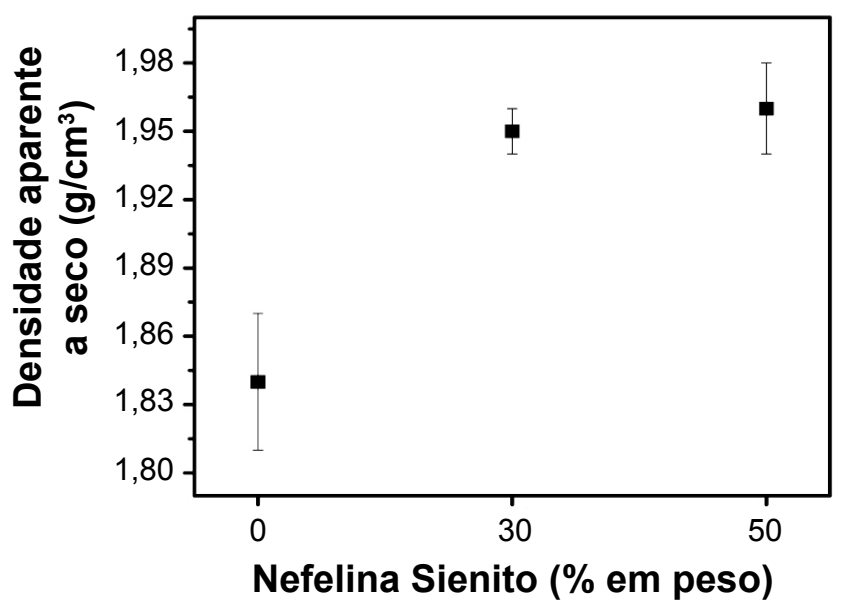

Figura 1: Densidade aparente a seco das cerâmicas.

[Figure 1: Dry bulk density of ceramics.]

água dentro da faixa de revestimento tipo grês. A $1200{ }^{\circ} \mathrm{C}$ a argila pura atinge a especificação de revestimento tipo semi-grês. A incorporação de 30 e $50 \%$ nefelina sienito possibilitou que a obtenção de revestimento tipo grês e porcelanato, respectivamente.

A Fig. 3 apresenta a tensão de ruptura à flexão das cerâmicas em função da temperatura de queima. Pode-se observar que a incorporação de nefelina sienito também melhorou a resistência mecânica da argila em todas as temperaturas investigadas. A argila pura só supera o valor mínimo recomendado para revestimento tipo semi-grês, 22 $\mathrm{MPa}$, a $1200^{\circ} \mathrm{C}$. A incorporação de nefelina sienito, mesmo com a quantidade mínima investigada de $30 \%$, possibilitou que a argila superasse o valor mínimo recomendado de tensão de ruptura à flexão para revestimento tipo porcelanato, 35 $\mathrm{MPa}$, a 1150 e $1200^{\circ} \mathrm{C}$.

A Fig. 4 apresenta a retração linear das cerâmicas em função da temperatura de queima. Pode-se observar que a incorporação de nefelina sienito reduziu a retração linear da

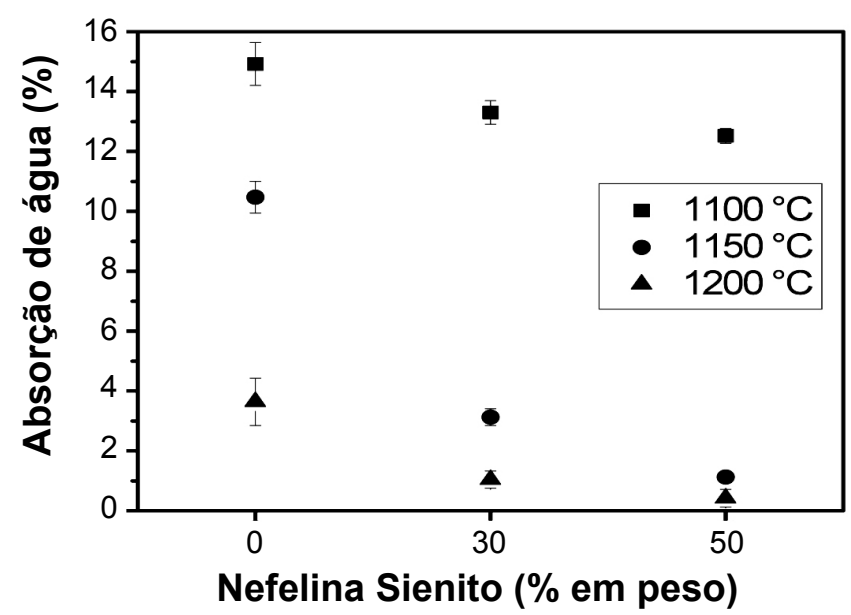

Figura 2: Absorção de água das cerâmicas em função da temperatura de queima

[Figure 2: Water absorption of the ceramics as a function the firing temperature.]

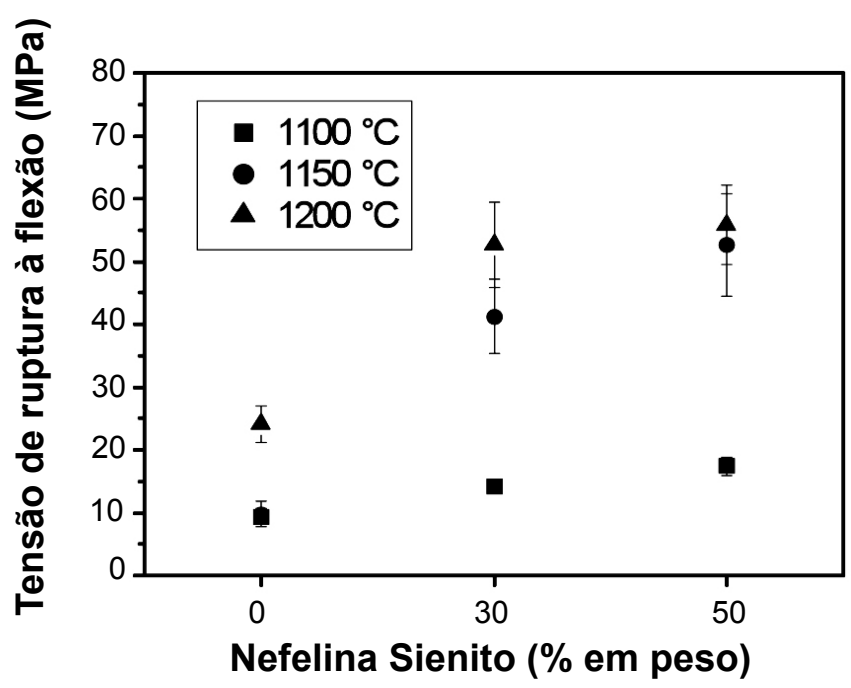

Figura 3: Tensão de ruptura à flexão das cerâmicas em função da temperatura de queima.

[Figure 3: Flexural rupture strength of the ceramics as a function the firing temperature.]

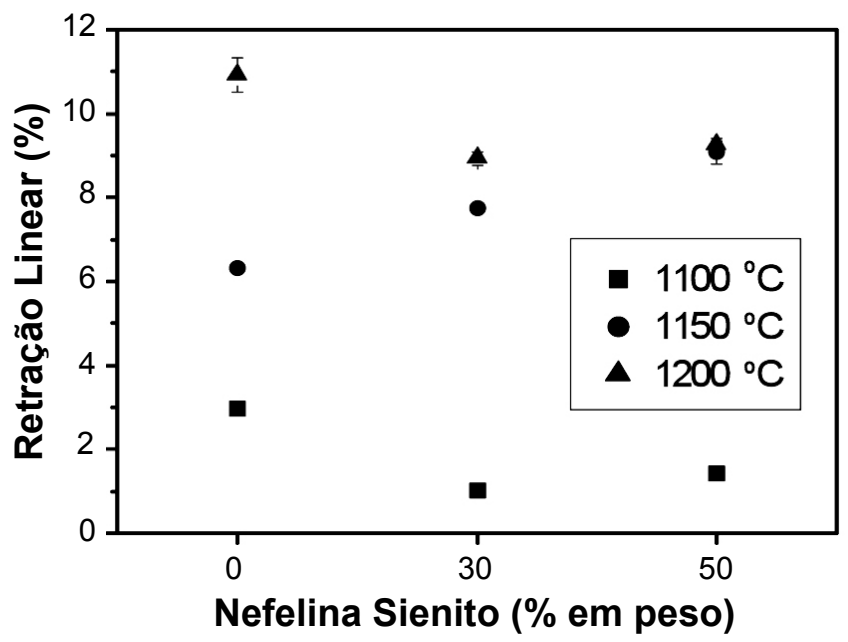

Figura 4: Retração linear das cerâmicas em função da temperatura de queima.

[Figure 4: Linear shrinkage of the ceramics as a function the firing temperature.]

argila nas temperaturas de 1100 e $1200{ }^{\circ} \mathrm{C}$. Já a $1150{ }^{\circ} \mathrm{C}$ o efeito foi ao contrário, ocorreu um incremento da retração linear da argila com a utilização de nefelina sienito. Este comportamento é possivelmente atribuído à formação de fase líquida bastante pronunciada a $1150{ }^{\circ} \mathrm{C}$, devido à fundência dos feldspatos presentes na nefelina sienito. Já a 1100 e $1200{ }^{\circ} \mathrm{C}$ o efeito fundente da nefelina sienito não se sobrepôs à retração da argila, que ocorre devido à perda de massa e às reações de sinterização, difusão no estado sólido e formação de fase líquida.

A seguir serão mostradas algumas características microestruturais das cerâmicas queimadas, tais como fases cristalinas de queima e micrografias da região de fratura. Os resultados mostram que as cerâmicas apresentam importantes transformações durante o processo de queima, com a formação de novas fases. A presença de poros e defeitos é 
também uma característica marcante na microestrutura das cerâmicas. Estes fatores contribuem fortemente para o comportamento físico e mecânico obtido relativamente às cerâmicas queimadas.

A Fig. 5 apresenta o difratograma de raios $\mathrm{X}$ da cerâmica A, argila pura, queimada a 1100,1150 e $1200{ }^{\circ} \mathrm{C}$. Nota-se a $1100{ }^{\circ} \mathrm{C}$ a presença de mica muscovita (M), feldspato potássico $\left(\mathrm{F}_{\mathrm{k}}\right)$, possivelmente a microclina, e de quartzo (Q). À exceção do feldspato potássico, que pode também ter sido formado durante a queima, todos os demais minerais são fase residuais, ou seja, presentes inicialmente como impurezas da própria argila. A $1150{ }^{\circ} \mathrm{C}$ nota-se o aparecimento de picos de difração correspondentes da mulita $(\mathrm{Mu})$ e desaparecimento dos picos da mica muscovita e ainda, a redução de intensidadedo feldspato potássico. Isto ocorre devido à fusão do feldspato potássico a 1150 ${ }^{\circ} \mathrm{C}$, com formação de fase líquida. A mulita é uma fase que aparece em conseqüência da queima, sendo proveniente da recristalização da metacaulinita. Com o aumento da temperatura, basicamente as fases cristalinas presentes na cerâmica A são a mulita e o quartzo. Nota-se um pico de baixa intensidade associado a um tipo de feldspato plagioclásio $\left(\mathrm{F}_{\mathrm{pl}}\right)$, possivelmente à anortita $(\mathrm{A})$, feldspato cálcico que apresente um elevado ponto de fusão. Era de se esperar a presença de leucita, fase proveniente da fusão incongruente da microclina. Entretanto, os principais picos de difração da leucita possivelmente estão sendo encobertos pelos minerais majoritários.

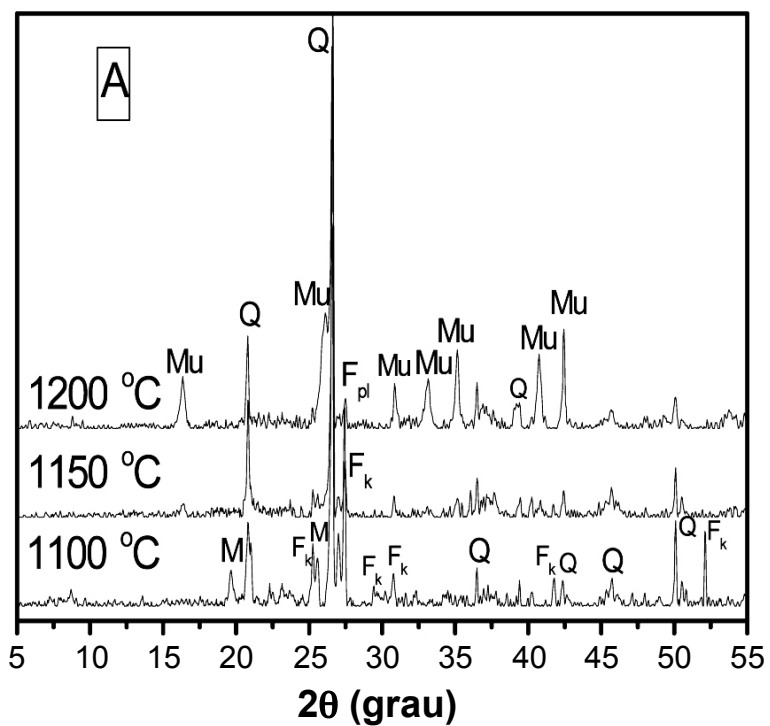

Figura 5: Difratogramas de raios X da cerâmica com argila pura, A, queimada a 1100,1150 e $1200^{\circ} \mathrm{C}$.

[Figure 5: $X$-ray diffraction patterns of the ceramic with pure clay, $A$, fired at 1100,1150 and $1200^{\circ} \mathrm{C}$.]

A Fig. 6 apresenta o difratograma de raios $\mathrm{X}$ da cerâmica A50N queimada a 1100,1150 e $1200{ }^{\circ} \mathrm{C}$. As principais alterações nas fases cristalinas de queima da cerâmica queimada a $1100{ }^{\circ} \mathrm{C}$ em comparação com a argila pura é a maior presença de picos de difração associados aos feldspatos, tanto o potássico quanto os plagioclásios. A $1150{ }^{\circ} \mathrm{C}$, assim como a argila pura, ocorre o desaparecimento da mica, bem como o surgimento da mulita. Já a $1200{ }^{\circ} \mathrm{C}$, fases cristalinas majoritárias remanescentes na cerâmica $\mathrm{A} 50 \mathrm{~N}$ são similares a cerâmica A, ou seja, quartzo, a mulita e anortita.

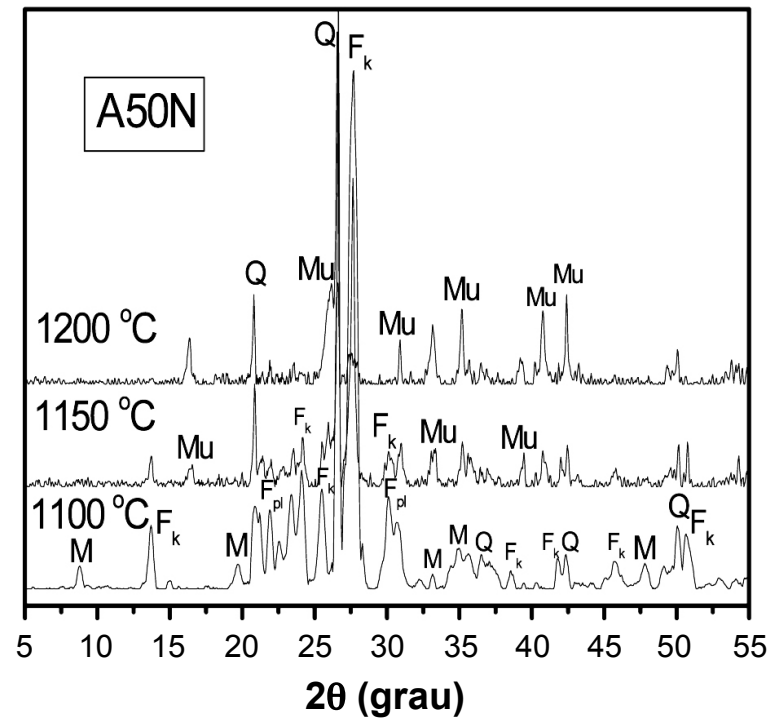

Figura 6: Difratogramas de raios X da cerâmica com 50\% de argila e $50 \%$ de nefelina sienito, A50N, queimada a 1100,1150 e $1200{ }^{\circ} \mathrm{C}$. [Figure 6: X-ray diffraction patterns of the ceramic with $50 \%$ of clay and $50 \%$ of nepheline-syenite, A50N, fired at 1100, 1150 and $1200^{\circ} \mathrm{C}$.]

A Fig. 7 mostra a superfície de fratura das cerâmicas A e A $50 \mathrm{~N}$ queimadas a $1100^{\circ} \mathrm{C}$. Nota-se para ambas as cerâmicas uma textura rugosa, a qual está associada a um processo de sinterização não totalmente consolidado, indicando que a formação de fase líquida não foi plenamente desenvolvida. A Fig. 8 mostra a superfície de fratura das cerâmicas A e A50N queimadas a $1150{ }^{\circ} \mathrm{C}$. É possível observar, em comparação com a Fig. 8, que ocorreu uma redução tanto na rugosidade das cerâmicas quanto na quantidade de defeitos. Já a 1200 ${ }^{\circ} \mathrm{C}$, Fig. 9 , nota-se que a cerâmica $\mathrm{A} 50 \mathrm{~N}$ já apresenta um alisamento da textura, com superfície de fratura plenamente vitrificada com poros isolados. Já a cerâmica A, argila pura, não apresenta o mesmo nível de vitrificação e ainda apresenta uma microestrutura com interconectividade de defeitos. Este comportamento diferenciado é devido à maior quantidade de feldspatos na formulação A50N provenientes da nefelina sienito que atua como fundente possibilitando assim, uma formação de fase líquida abundante.

Como considerações finais, pode-se afirmar que os resultados deste trabalho são bastante favoráveis a uma formulação de revestimento para pavimento vitrificado utilizando uma argila caulinítica, incorporada com nefelina sienito. Em comparação com o trabalho anterior [10], foi observado que as formulações com nefelina alcançaram menores valores de absorção de água e maiores valores de resistência mecânica numa temperatura $25^{\circ} \mathrm{C}$ inferior. Isto pode ser atribuído ao maior empacotamento a seco das cerâmicas alcançadas neste segundo trabalho, que possibilitou uma melhor sinterização na etapa de queima. 

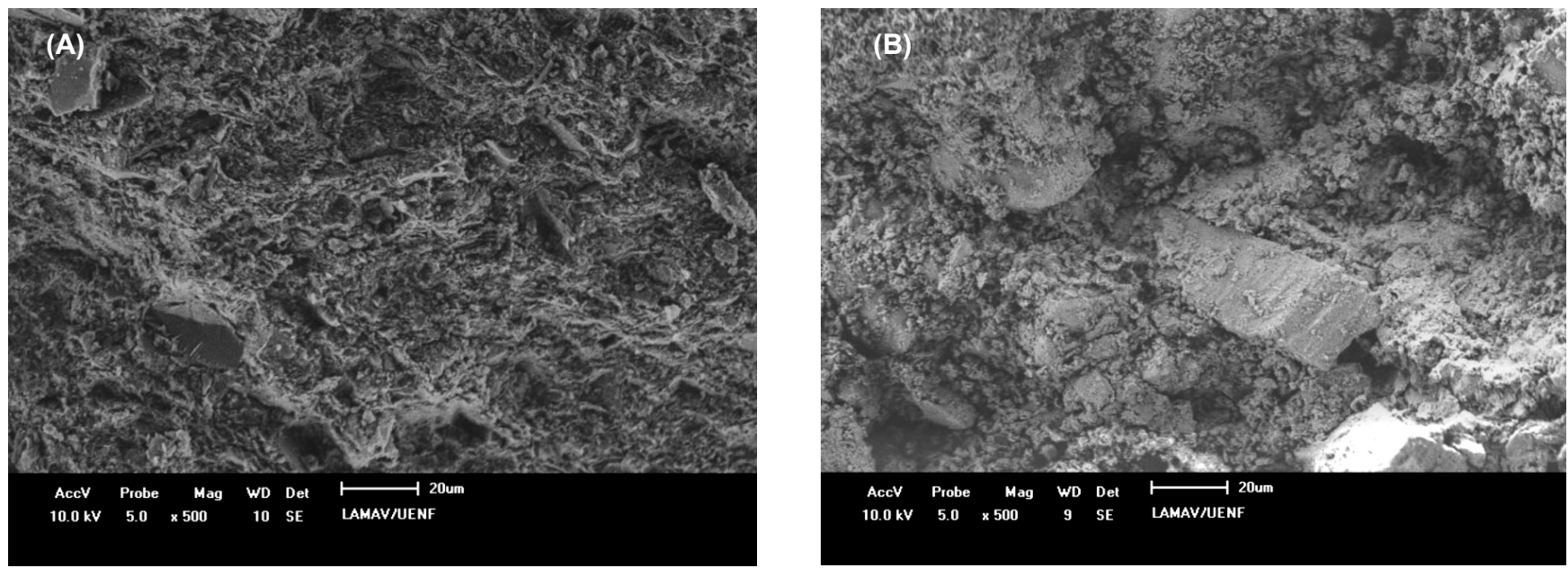

Figura 7: Micrografias obtidas por microscopia eletrônica de varredura da região de fratura das cerâmicas A, argila pura,e A50N, argila com 50\% de nefelina sienito, queimadas a $1100{ }^{\circ} \mathrm{C}$.

[Figure 7: SEM micrographs of the fracture region of the ceramics A, pure clay, and A50N, clay with $50 \%$ of nepheline-syenite, fired at $1100^{\circ} \mathrm{C}$.]
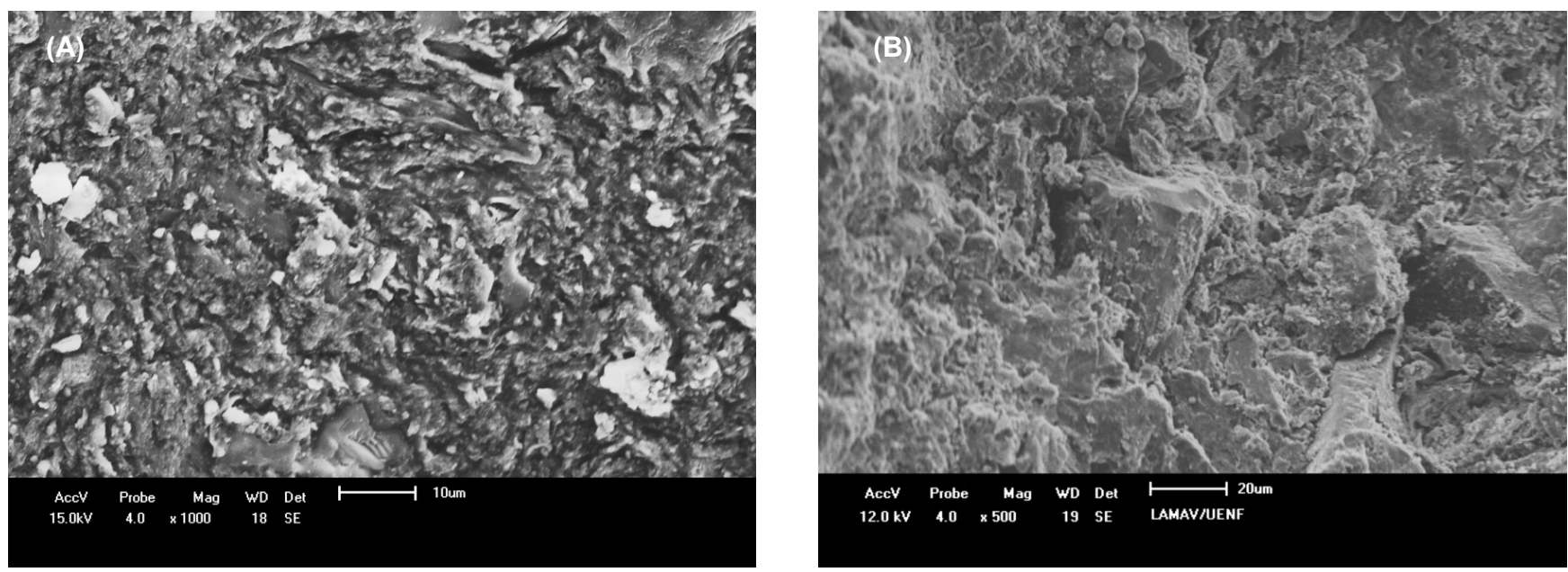

Figura 8: Micrografias obtidas por microscopia eletrônica de varredura da região de fratura das cerâmicas A, argila pura,e A50N, argila com 50\% de nefelina sienito, queimadas a $1150{ }^{\circ} \mathrm{C}$.

[Figure 8: SEM micrographs of the fracture region of the ceramics A, pure clay, and A50N, clay with $50 \%$ of nepheline-syenite, fired at $1150^{\circ} \mathrm{C}$.]
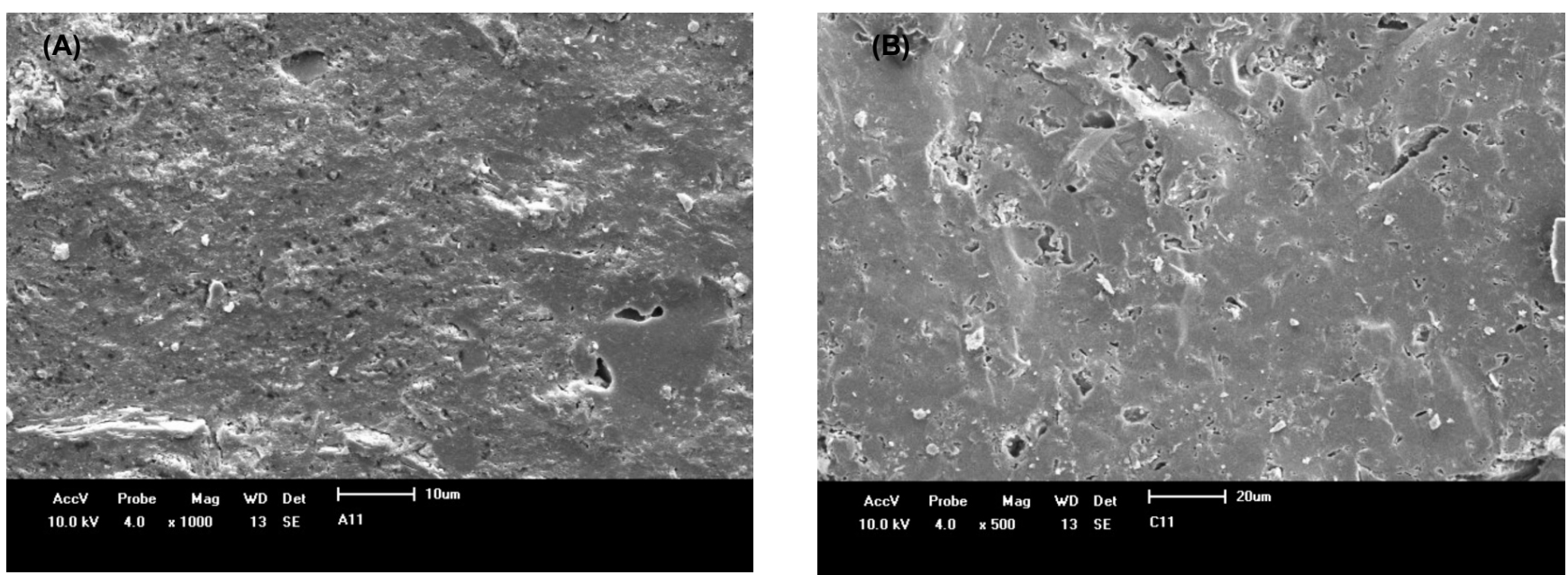

Figura 9: Micrografias obtidas por microscopia eletrônica de varredura da região de fratura das cerâmicas A, argila pura, e A50N, argila com 50\% de nefelina sienito, queimadas a $1200{ }^{\circ} \mathrm{C}$.

[Figure 9: SEM micrographs of the fracture region of the ceramics A, pure clay, and A50N, clay with $50 \%$ of nepheline-syenite, fired at $1200{ }^{\circ} \mathrm{C}$.] 


\section{CONCLUSÕES}

A argila pura só alcançou especificação de revestimento cerâmico, ainda do tipo semi-grês, a $1200{ }^{\circ} \mathrm{C}$. Além de ser uma temperatura extremamente elevada e atípica a nível industrial para esta tipologia de revestimento, a retração linear foi muito elevada. A incorporação de nefelina sienito possibilitou uma melhora significativa nas propriedades de queima da argila caulinítica em todas as temperaturas investigadas. Com $30 \%$ de nefelina sienito a $1150{ }^{\circ} \mathrm{C}$ foi possível alcançar a especificação de absorção de água e de tensão de ruptura à flexão de revestimento tipo semigrês; com $50 \%$ de nefelina sienito a $1150{ }^{\circ} \mathrm{C}$ foi possível alcançar a especificação de absorção de água e de tensão de ruptura à flexão de revestimento tipo grês. Esta combinação quantidade de fundente/temperatura de queima é a mais indicada para um eventual teste em escala industrial para a obtenção desta tipologia de revestimento; já a $1200{ }^{\circ} \mathrm{C}$, tanto com $50 \%$ de nefelina sienito foi possível também alcançar a especificação de absorção de água e de tensão de ruptura à flexão de revestimento do tipo porcelanato.

\section{AGRADECIMENTOS}

Ao CNPq, Proc. 470122/2008-0.

\section{REFERÊNCIAS}

[1] G. P. Emiliani, F. Corbara, "Tecnología Cerámica - Le Materia Prime”, Gruppo Editoriale Faenza Editrice, Faenza,
Italy (1999) 51.

[2] Associação Brasileira de Normas Técnicas - ABNT, "Placas Cerâmicas para Revestimento - especificação e métodos de ensaio", NBR13818, Rio de Janeiro, RJ (1997) $78 \mathrm{p}$.

[3] S. C.A. França, J. A. Sampaio, Anais do XIX ENTMME, Recife, PE (2002) 2.

[4] E. D. Lynch, A. W. Allen, J. Am. Ceram. Soc. 33, 4 (1950) 117.

[5] S. Sabedot, A. R. Volkmann, C. H. Sampaio, Anais 60 Cong. An. ABM, Belo Horizonte, MG (2005).

[6] F. Burat, O. Kangal, G. Onal, Minerals Eng. 19, 4 (2006) 370-371.

[7] L. Esposito, A. Salem, A. Tucci, A. Gualtieri, S.H. Jazayeri, Ceram. Int. 31, 2 (2005) 233-240.

[8] A. Salem, S. H. Jazayeri, E. Rastelli, G. Timellini, J. Mater. Proc. Techn. 209, 3 (2009) 1240-1246. [9] D. M. Ibrahim, E. H. Sallam, A. A. Khalil, S. M. H. Naga, Ceram. Int. 7, 2 (1981) 69-72.

[10] C. M. F.Vieira, J. B. Soares, S. N. Monteiro, Cerâmica 54 (2008) 184-192.

[11] S. N. Monteiro, C. M. F. Vieira, Tile \& Brick Int. 18, 3 (2002) 152-157.

[12] America Society for Testing and Materials - ASTM, "Water Absorption, Bulk Density, Apparent Porosity, and Apparent Specific Gravity of Fired Whiteware Products", C 373-72 (1972).

[13] American Society for Testing and Materials - ASTM, "Flexural Properties of Ceramic Whiteware Materials", C 674-77 (1977).

(Rec. 17/03/2010, Rev. 16/04/2010, Ac.07/05/2010) 